\title{
Coexpression of Wilms' tumor suppressor 1 (WT1) and androgen receptor (AR) in the genital tract of human male embryos and regulation of AR promoter activity by WT1
}

\author{
Birgit Köhler, Anne-Lise Delezoide ${ }^{1}$, Brigitte Boizet-Bonhoure ${ }^{2}$, Michael J McPhaul ${ }^{3}$, \\ Charles Sultan and Serge Lumbroso
}

Service d'Hormonologie and Institut National de la Santé et de la Recherche Médicale U540, CHU Montpellier, 34295 Montpellier, France

${ }^{1}$ Laboratoire de Biologie de Développement, Hôpital Robert Debré, 75674 Paris, France

${ }^{2}$ Institut de Génétique Humaine, 34295 Montpellier, France

${ }^{3}$ Division of Endocrinology and Metabolism, University of Texas, Dallas, Texas 75390-8857, USA

(Requests for offprints should be addressed to B Köhler who is now at Abteilung für Pädiatrische Endokrinologie, Kinderklinik, Charité CVK, Augustenburger Platz 1, 13353 Berlin, Germany; Email: birgit.koehler@ charite.de; Serge Lumbroso who is now at Laboratoire de Biochimie, Hôpital Caremeau, CHU Nimes, 30029 Nimes, France; Email: serge.lumbroso@chu-nimes.fr)

\begin{abstract}
The Wilms' tumor suppressor 1 (WT1) is one of the key regulators of early male genital development. The androgen receptor (AR) is the major local factor responsible for the development of the male genitalia. As a subset of patients, with WT1 mutations and virilization defects, were found to present normal testosterone producing testes after birth, which suggests androgen resistance, we hypothesized that WT1 and AR might functionally interact during the development of the external genitalia. Coexpression of WT1 and AR was found in the mesenchyme surrounding the urogenital sinus, the mesonephros, and the Müllerian duct at 7 weeks p.c. and in the epididimys, vas deferens, and the gubernaculum testes from 13 to 27 weeks p.c. in human male embryos. A modification of AR expression by WT1 (WT1 $/ /+$, WT1 $+/-$, and WT1+/ - R394W) was seen in CV1, Hela, LNCaP, and T293 cells. WT1 was shown to increase or decrease AR expression depending on the cell line (1.6- to 3.7-fold). In this study, we consider LNCaP and T293 cells as the most physiological cell system, as both originate from the human urogenital tract. In these cell lines, a repressional effect of the mutant WT1 +/ - R394W (0.5-fold) on AR expression in comparison to the wild-type WT1 +/ - could be demonstrated. From our data, we conclude that a functional interaction of WT1 and AR might play a role during the development of the male external genitalia, but as the regulatory effects were moderate most likely in concert with other local cofactors.
\end{abstract}

Journal of Molecular Endocrinology (2007) 38, 547-554

\section{Introduction}

The Wilms' tumor suppressor 1 (WT1) is an early expressed transcription factor, which plays a major role in urogenital development and function in mammals (Kreidberg et al. 1993). It belongs to the zinc finger family of transcription factors, with four DNA/RNAbinding zinc fingers at its carboxy-terminal end (Call $e t$ al. 1990, Gessler et al. 1990). The WT1 gene was cloned in 1990 and may encode 24 protein isoforms through a combination of alternative splicing, alternative translational start sites, and RNA editing (Scharnhorst et al. 2001). The two major isoforms, with either an insertion $(+\mathrm{KTS})$ or exclusion ( - KTS) of lysine, threonine, and serine residues between zinc fingers 3 and 4, are generated through alternative splicing of exon 9 . The WT1-KTS isoform mainly plays a role in transcriptional activation and the WT1 + KTS isoform in RNA processing (Hastie 2001). Diverging data exist concerning the functional role of WT1 on transcription of target genes, since several studies showed that WT1 can act as either a transcriptional activator or a repressor both in vitro and in vivo (Scharnhorst et al. 2001, Wagner et al. 2003). Since the cloning of WT1, mutations have been described in numerous patients with syndromes associated with Wilms' tumor and/or nephropathy (WAGR (Wilms tumor, aniridia, genitourinary abnormalities, mental retardation); Denys-Drash and Frasier syndrome; Little \& Wells 1997, Jeanpierre et $a l$. 1998). In addition to kidney disease, WT1 mutations result in $\mathrm{XY}$ individuals in various degrees of undervirilization ranging from ambiguous genitalia with severe penoscrotal hypospadias to complete female genitalia. Their gonadal phenotype can vary from normally developed testes through partial gonadal dysgenesis to streak gonads with absent or incomplete testicular descent (Pelletier et al. 1991, Barbaux et al. 1997, Little \& Wells 1997). Together with SRY (sex 
determining region $\mathrm{Y}$ ), Dax1 (DSS-AMC critical region on the $\mathrm{X}$ chromosome 1, gene 1), SF-1 (steroidogenic factor 1), and Sox9 (SRY-related HMG-box gene 9), WT1 is one of the key regulators in human testes determination (Wagner et al. 2003). In vitro studies showed that the WT1 - KTS isoform interacts with SF-1 and Dax1 to upregulate or downregulate anti-Müllerian hormone (AMH) expression respectively, and can activate SRY, SF-1, and Dax1 gene expression (Nachtigal et al. 1998, Kim et al. 1999, Hossain \& Saunders 2001, Wilhelm \& Englert 2002).

After testes determination, the androgen receptor (AR) together with the $\mathrm{AMH}$ is the major regulating factor in the sex differentiation pathway leading to the male phenotype of the internal and external genital tracts. The phenotype of XY males with WT1 mutations led us to speculate that an interaction between WT1 and the AR might play a role in sex differentiation. Indeed, a subset of XY patients with severe hypospadias due to WT1 defects present normal androgen producing testes and resemble patients with partial androgen insensitivity (Kohler et al. 2001, Lim et al. 2001, Melo et al. 2002). In addition, the AR promoter is known to contain several putative WT1-binding sites (Shimamura et al. 1997). Thus, we hypothesize, that in patients with WT1 mutations and normal androgen production, a defective interaction between WT1 and AR might result in malformation of the male external genitalia during embryonic development. To address this hypothesis, we first investigated WT1 and AR expression in the internal and external genital tracts in human male embryos during the sensitive period of sex differentiation. Subsequently, we examined the regulation of $A R$ gene transcription by WT1 in vitro.

\section{Materials and methods}

\section{Human embryos}

Human male embryos were collected from legally terminated pregnancies in agreement with the French law and Ethic Committee recommendations and following the informed consent of the parents. Studies were performed on embryos of 7, 13, 19, 25, and 27 weeks state of development (SD). Tissues were fixed with $4 \%$ paraformaldehyde, embedded in paraffin, and sectioned $(4 \mu \mathrm{m})$.

\section{Immunohistochemistry}

Immunohistochemical staining of WT1 and AR was performed in the developing external genitalia at 7 weeks SD and in the internal genitalia at 7, 13, 19, 25, and 27 weeks SD. The embryonic sections were deparaffinized and rehydrated. Antigen retrieval was performed in $0.01 \mathrm{M}$ EDTA ( $\mathrm{pH} \mathrm{7.4)}$ ) at $100^{\circ} \mathrm{C}$ for $1 \mathrm{~h}$ and endogenous peroxidase activity was blocked with
$3 \%$ hydrogen peroxide. To reduce nonspecific binding, the slides were blocked with goat serum (dilution 1:40) in $0.5 \%$ bovine $\gamma$-globulin (Sigma-Aldrich). The sections were incubated with $4 \mu \mathrm{g} / \mathrm{ml}$ rabbit polyclonal anti-WT1 antibody (C-19, Santa Cruz Biotechnology, Santa Cruz, CA, USA) or $8 \mu \mathrm{g} / \mathrm{ml}$ rabbit polyclonal antiAR antibody (N-20, Santa Cruz Biotechnology) for $1 \mathrm{~h}$ at room temperature. Antigen visualization was performed with the streptavidin-biotin-horseradish peroxidase system (DAKO LSAB 2 System, Carpinteria, CA, USA). Between the different steps, the samples were washed with $0.05 \%$ Tween/PBS. The sections were counterstained with hematoxylin and as a negative control, normal rabbit immunoglobulin G (IgG) was used instead of the primary antibody.

For immunofluorescent labeling, the embryonic sections were saturated in $10 \% \mathrm{BSA} / \mathrm{PBS}$ containing $0.3 \%$ Triton and $3 \%$ human serum for $30 \mathrm{~min}$ after antigen retrieval. Subsequently, the sections were incubated overnight at room temperature with both polyclonal rabbit anti-WT1 (C19, Santa Cruz Biotechnology) and monoclonal mouse anti-AR (441, Santa Cruz Biotechnology) antibodies (dilution in the ratio of $1: 100$ in PBS/1\% BSA). The slides were washed in PBS and the primary antibodies were visualized with Alexa 564-conjugated anti-rabbit (red) and Alexa 488conjugated anti-mouse antibodies (green; dilution in the ratio of 1:1000; Molecular Probe, Invitrogen) for $30 \mathrm{~min}$. Immunofluorescent staining was analyzed with a Leica DMR2 microscope.

\section{Plasmids}

The mouse WT1 isoforms, containing exon 5 and either insertion $(\mathrm{WT} 1+/+)$ or exclusion of KTS $(\mathrm{WT} 1+/-)$, were cloned in pCMV (human cytomegalovirus promoter) (pCMV-mWT + / + and pCMV-mWT1 + / - ; gift from Dr N D Hastie, Edinburgh, England). The pCMV empty vector was produced by removing the WT1 $+/-$ insert of pCMV-mWT1+/- by XbaI digestion. The WT1+/cDNA bearing the R394W mutation was obtained by standard site-directed mutagenesis using the QuickChange site-directed mutagenesis kit (Stratagene, La Jolla, CA, USA). For construction of the human AR reporter vector, the AR promoter fragments $(-2100$ to $+898)$ and $(-571$ to +898$)$ were cloned into the pGL2 vector, in fusion with the luciferase gene (hARpr-2100luc and hARpr-571luc). The AR full-length cDNA was cloned into the pSG5 vector (pSG5-hAR). The androgenresponsive element, containing the $\mathrm{AR}$ inducible mousemammary-tumor virus sequence, was cloned into the $\mathrm{pFC}$ luciferase vector (pFC31-luc; gift from Dr H Richard, Toulouse, France). pCMV- $\beta$-galactosidase was used as a transfection control. Plasmids for transfection were purified with the maxiprep reagent system (Qiagen). 


\section{Cell culture and transfection assays}

CV1 (green monkey kidney cell line), Hela (human cervical carcinoma cells line), and T293 (human embryonic kidney cell line) cells were cultured in Dulbecco's modified Eagle medium containing 5\% fetal calf serum for CV1 cells or 10\% for Hela and T293 cells. LNCaP cells (human prostate cancer cell line) were cultured in RPMI $10 \%$. For transfection, the cells were plated in 12-well plates and transfected at $80 \%$ confluence with Lipofectamine according to the manufacturer's instructions (Invitrogen). Different amounts of WT1 $(50,100,250$, and $500 \mathrm{ng})$ were cotransfected with $250 \mathrm{ng}$ hARpr-luc to test the quantitative effects of WT1 on the AR promoter (Fig. 3B). Subsequently, cotransfections were performed with $500 \mathrm{ng}$ empty vector, pCMV-WT1 $+/+$, pCMV-WT1 + / -, or pCMV-WT1 + / - R394W (as this quantity showed the strongest effect on AR expression), $250 \mathrm{ng}$ hARpr-luc, and $100 \mathrm{ng} \beta$-galactosidase (Fig. 3B). Luciferase activity was measured with the Centro LB 960 luminometer (Berthold Technologies, Bad Wildbad, Germany). hARpr-luc and pFC31-luc activities were expressed as relative luciferase activities per $\beta$-galactosidase unit. Each experiment was performed three times in duplicates. Error bars represent the standard error of the mean (土s.E.M).

\section{Results}

\section{WT1 and AR expression in the internal and external genitalia of human embryos}

In the external genitalia at 7 weeks, WT1 expression was found in mesenchymal cells surrounding the urogenital sinus (UGS). In the genital tubercle and the developing urethra, no WT1 expression was detectable (Fig. 1A). AR staining was intense in the genital tubercle and the mesenchyme around the UGS, but weak in the urethral epithelium (Fig. 1B). Coexpression of WT1 and AR in the external genitalia was analyzed by immunofluorescence studies (Fig. 1, Ia-IIc). WT1- and AR-staining
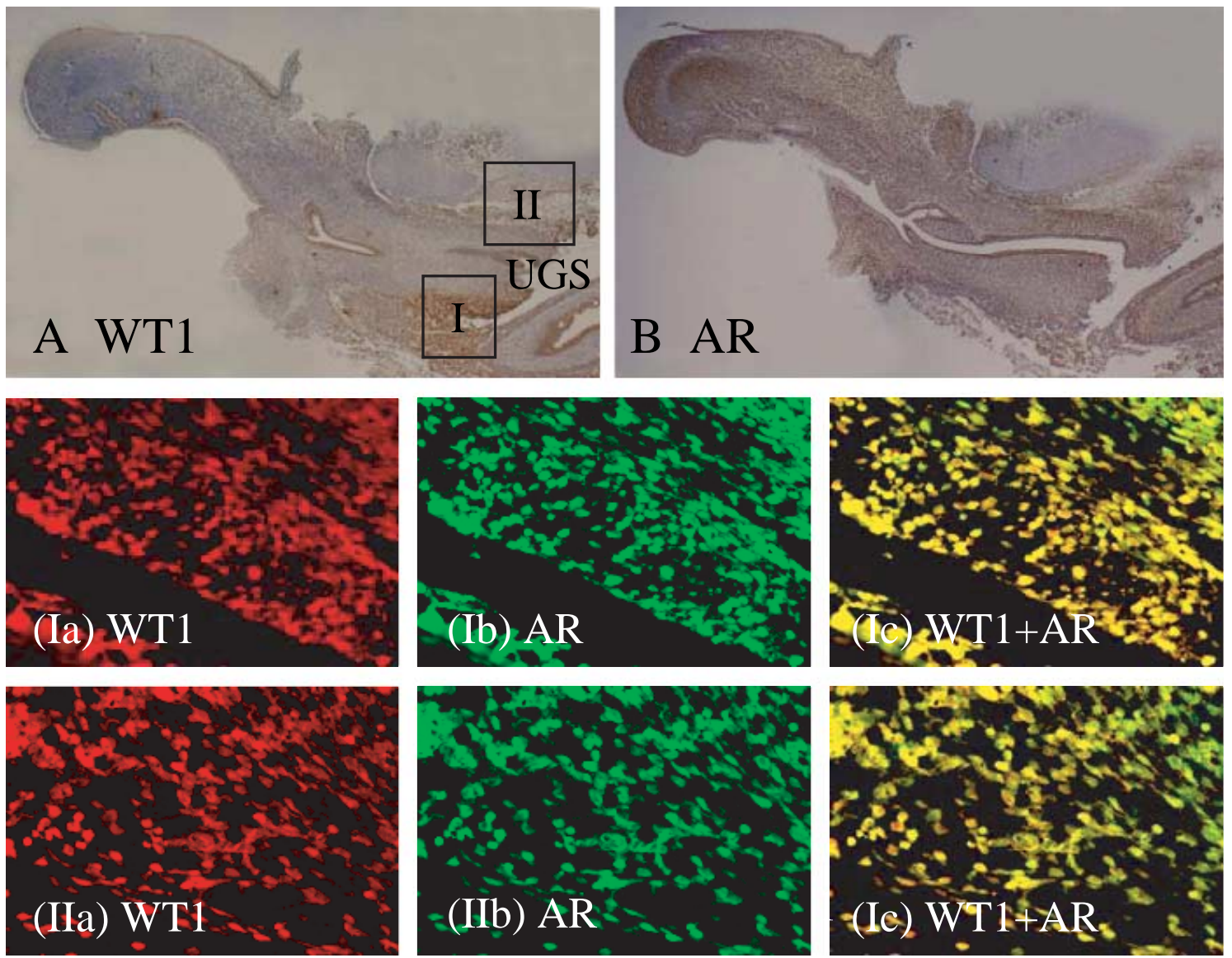

Figure 1 The expression of WT1 and AR in the external genitalia at 7 weeks SD. WT1 $(A)$ and AR (B) were expressed in mesenchymal cells surrounding the urogenital sinus (UGS). AR expression was visible in a ubiquitous pattern in the genital tubercle (B). The boxes I and II represent the area of WT1 and AR coexpression shown by immunofluorescence. The images la, Ila, Ib, and Ilb show immunofluorescent staining of WT1 (red) and AR (green) respectively. Merge images (Ic and IIc) depict WT1 and AR coexpression (yellow) in the mesenchymal cells surrounding the UGS. Magnification: A and B $\times 2.5$ and la-llc $\times 40$. 
images (Ia, Ib and IIa, IIb) were merged and confirmed that $\mathrm{WT} 1$ and AR were coexpressed in the mesenchyme of the UGS (Fig. 1, Ic and IIc).

In the internal genitalia at this early stage of 7 weeks, WT1 and AR were both expressed in the mesenchymal cells of the mesonephros and in Müllerian ducts, while only AR was detected in the Wolffian ducts (Fig. 2A and B). At 13 weeks, weak WT1 staining was seen in a subset of interstitial cells between the tubules of the epididymis, whereas AR staining was intense in interstitial cells, especially cells surrounding the tubules and in the tubular epithelium (Fig. 2D and E). In the vas deferens, interstitial cells surrounding the duct were positively stained for WT1 and AR. WT1 staining was absent in the epithelial layer of the vas deferens, in contrast to AR staining was intense in this epithelium (Fig. 2G and H). In the gubernaculum testis, both WT1 and AR expressions were detected (Fig. 2J and K). Thus, coexpression of WT1 and AR was visible in the Müllerian duct, interstitial cells of the mesonephros, epididymis, vas deferens, and gubernaculums testis. Coexpression of WT1 and AR in the gubernaculum testis was confirmed by immunofluorescence (Fig. 2U-O).

Data for WT1 and AR expression in these compartments were only shown at 13 weeks, as the same expression patterns were continuously seen in embryos from 13 to 27 weeks.
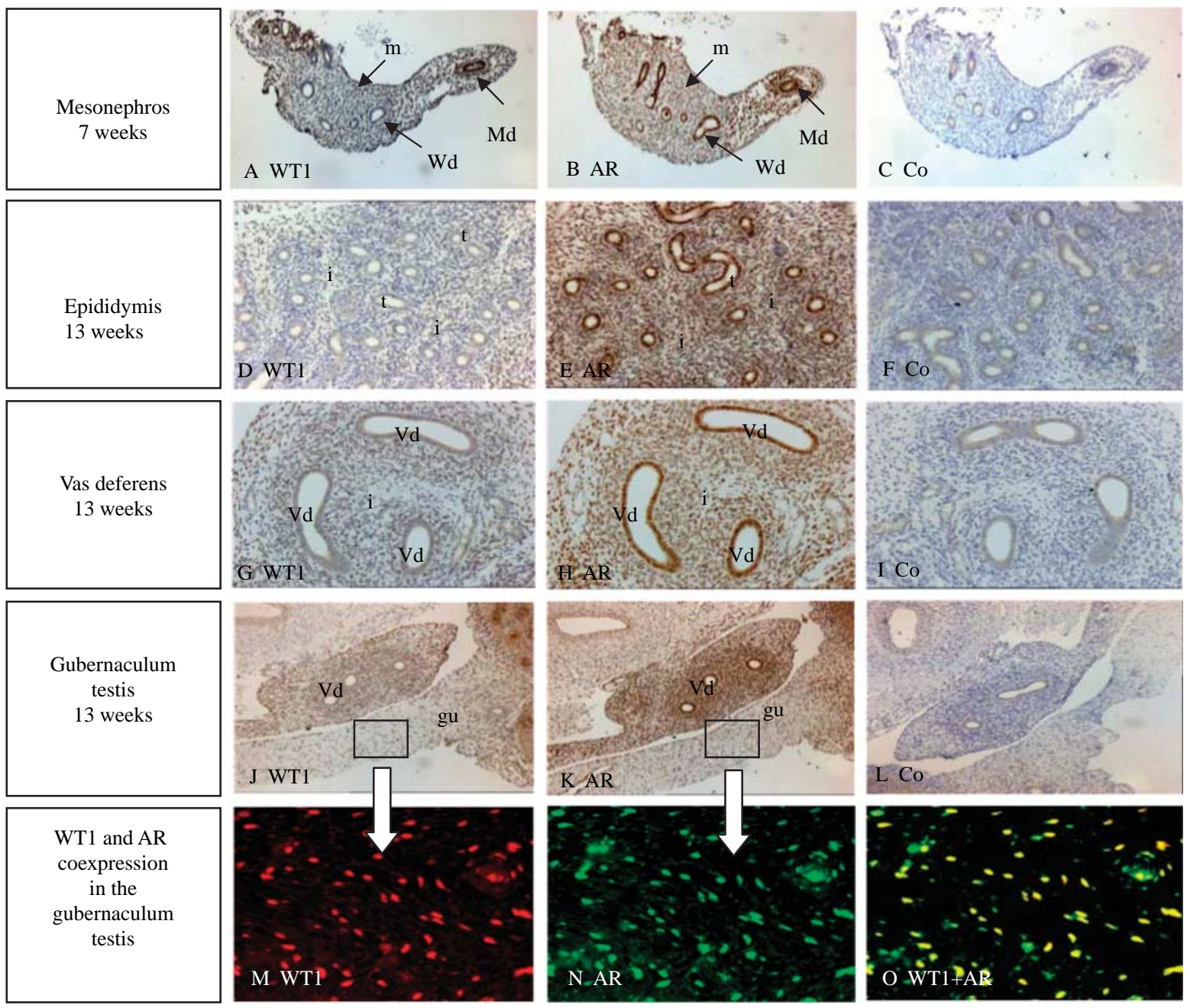

Figure 2 The expression of WT1 and AR in the internal genitalia at 7 and 13 weeks SD. In the mesonephros, WT1 and AR were coexpressed in mesenchymal cells $(m)$ and the Müllerian duct epithelium (Md) $(A)$. The AR was also expressed strongly in Wolffian duct epithelium (Wd) (B). In the epididymis, WT1 and AR were coexpressed in interstitial cells (i). In addition, the AR was expressed strongly in tubular epithelium (t) $(D, E)$. In the vas deferens (vd), WT1 and AR were coexpressed in interstitial cells surrounding the duct (i) and AR staining was strong positive in ductal epithelium $(\mathrm{G}, \mathrm{H})$. In the gubernaculum testis (gu), WT1 and AR staining was visible in single cells ( $\mathrm{J}$, $\mathrm{K}) .(\mathrm{C}),(\mathrm{F}),(\mathrm{I})$, and $(\mathrm{L})$ represent negative controls respectively. (M) and (N) represent WT1 (red) and AR (green) expression in the gubernaculum testis by immunofluorescence respectively. Coexpression of WT1 and AR (yellow) is shown by merge images of (M) and (N). (O) Magnification: $A-L \times 10$ and $M-O \times 40$. 


\section{Modification of AR expression by WT1 in vitro}

In order to study whether WT1 modifies AR expression at the transcriptional level, we used two AR promoter constructs in transfection experiments. The long AR promoter (hARpr -2100 to +838 ) containing two previously described WT1-binding sites at position -352 and +427 and the short AR promoter (hARpr -571 to +304$)$ only containing the -352 site (Shimamura et al. 1997; Fig. 3A), showed the same

A

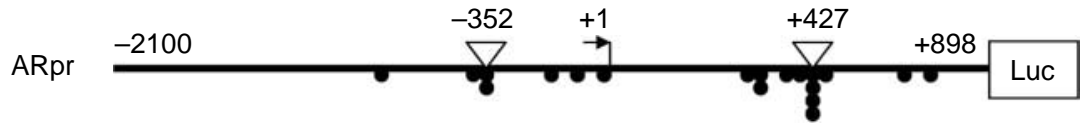

CV1

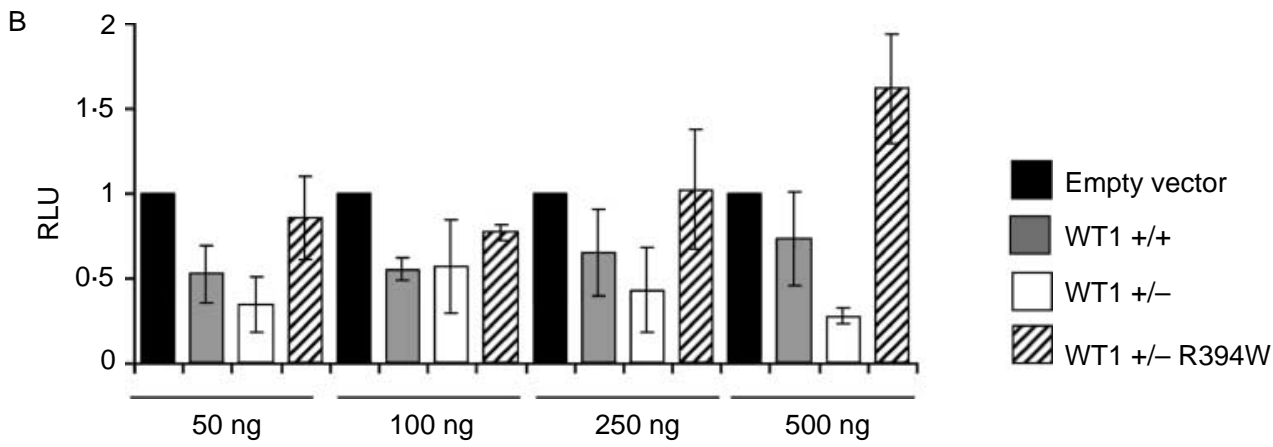

C

CV1

Hela
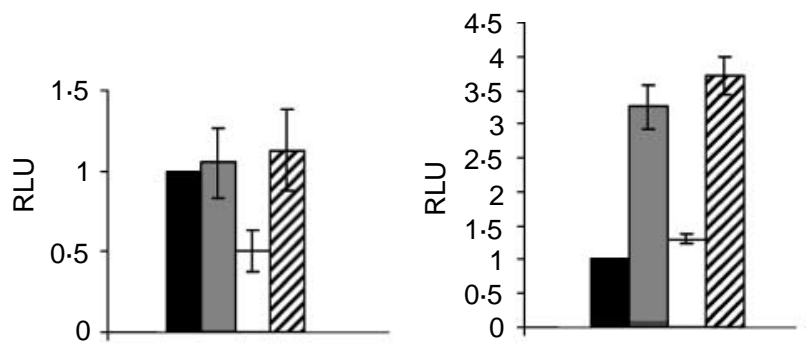

LNCaP

T293
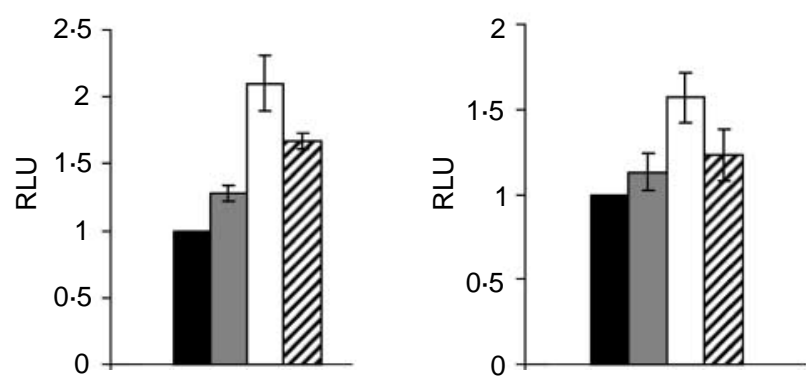

Figure 3 Transcriptional regulation of the AR gene by WT1 in vitro. (A) Schematic representation of the promoter construct, which was used in this study. -352 and +427 represent the position of putative WT1-binding sites (according to Shimamura et al. 1997). (B) Modification of $A R$ gene transcription by increasing quantities of WT1 $(50,100,250$, and $500 \mathrm{ng})$ in CV1 cells. (C) Modification of the AR gene transcription by WT1 $(500 \mathrm{ng})$ in different cell lines (CV1, Hela, LNCaP, and T293). The relative luciferase activity (RLU) of the empty vector pCMV was set at 1 . Results are given as relative activation of the reporter by the expression constructs when compared with the empty vector (pCMV). All values represent the means of three separate transfection experiments ( \pm S.E.M). 
basal transcriptional activity in different cell lines. No differences of activation or repression of the two promoter constructs were seen (data not shown) and in the following experiments, we used the long AR promoter (hARpr -2100 to +838 ). Since exon 5 did not significantly modify WT1 function (mice with deletion of exon 5 did not show developmental abnormalities; Natoli et al. 2002, Wagner et al. 2003), only the effect of the major +KTS and - KTS WT1 isoforms on the AR promoter activation was studied. One of the most frequent mutations in Denys-Drash syndrome, the inactive - KTS mutant R394W, which is known to lose its DNA binding and transactivation capacities, was also studied (Little et al. 1995). Four different cell lines (CV1, Hela, LNCaP, and T293), which expressed low levels of endogenous WT1 as demonstrated by western blot analysis were used. AR expression was positive in Hela, LNCaP, and T293 cells, but absent in CV1 cells (data not shown).

In CV1 cells, no activity of WT1 $1+$ + and WT $1+/-$ R394W on the human AR promoter was found, while $\mathrm{WT} 1+/-$ induced a $50 \%$ repression of the basal transcription of the promoter. Conversely, in Hela cells, the WT1 $+/-$ isoform had no activity, whereas both $\mathrm{WT} 1+/+(3.2$-fold) and the WT1+/- R394W (3.7fold) mutant strongly activated the AR promoter. In LNCaP and T293 cells, the WT1 $+/+$ showed no activation, but the WT1 $+/-$ activated AR transcription 2.1- and 1.6-fold respectively, and the WT1 $+/-$ R394W mutant had a repressive effect when compared with the wild-type isoform $+/-(0.5$-fold; Fig. 3C).

\section{Discussion}

In this study, we showed for the first time WT1 and AR coexpression during embryonic development of the external and internal genitalia in human male embryos. Furthermore, we presented data on a possible regulation of AR promoter activity by WT1.

WT1 and AR were coexpressed in mesenchymal cells surrounding the UGS in the external genitalia before closure of the male urethra, at 7 weeks SD (Fig. 1). In the internal genitalia, coexpression was present in mesenchymal cells of the mesonephros and in the Müllerian duct epithelium. From 13 to 27 weeks, coexpression was observed in interstitial cells of organs which derived from the Wolffian duct (epididymis and vas deferens) and in the gubernaculum testis (Fig. 2).

The coexpression pattern of WT1 and AR at the base of the genital tubercle, in the vas deferens, and in the gubernaculum testis might represent the physiological basis for a functional interaction between WT1 and AR during genital organogenesis. A disturbed interaction might explain the severe penoscrotal hypospadias and impaired testicular descent in patients with WT1 mutations and normal testosterone production (Lim et al. 2001).

These expression data led us to investigate WT1 regulation of AR promoter activity. We examined the WT1 transcriptional activity on AR expression in different cell lines (CV1, Hela, T293, and LNCaP). In all cell lines, WT1 expression was weak. AR expression was absent in CV1 cells and moderate to strong in Hela, T293, and LNCaP cells (data not shown). Different effects - activation or repression - of WT1 on AR expression were found in the cell lines according to previous studies (Reddy et al. 1995, Menke et al. 1998). In AR-negative CV1 cells, a strong repression of $\mathrm{WT} 1+/-$ (twofold), but no effect of WT1 $+/+$ and $\mathrm{WT} 1+/-\mathrm{R} 394$ on the AR promoter was found. In Hela cells, both the $+/+$ isoform and the mutant strongly activated the AR promoter (3.2- and 3.7-fold). The results in Hela cells stand in contrast to the results of the study by Shimamura $e t$ al., where a repression of $\mathrm{WT} 1+/+$ on the AR promoter was described (Shimamura et al. 1997). The contradictory effects of $\mathrm{WT} 1+/+$ in Hela cells in the two studies could be explained by the different quantities of the transfected WT1 plasmids or different lengths of the AR promoters which were used. In LNCaP and T293 cells, the + / isoform (1.6- and 2.1-fold) showed an activating effect; however, the mutant had a repressive effect (0.5-fold) when compared with the wild type (Fig. 3C). In this study, we consider LNCaP and T293 cells closest to physiology for urogenital development, as both originate from the human urogenital tract and express $\mathrm{AR}$ and WT1. Consequently, the transcriptional activity of WT1 on the AR promoter in these cells could represent a basic in vitro model for a functional role of WT1 through AR during urogenital development. We suggested that WT1 could directly activate AR transcription. But, regarding the low activation of the wild-type WT1 and the slight repression of the mutant when compared with the wild type in LNCaP and T293 cells, other cofactors, as suggested for androgen insensitivity syndrome (AIS), are probably involved in this process. It was hypothesized that in AIS, cofactors of the AR might modify androgen action, as in a large subset of patients no mutations of the AR were detected and often no correlation of the genotype with the phenotype was found (Adachi et al. 2000, Deeb et al. 2005). Recently, it was shown for AR mutations in partial AIS, that addition of the transcription intermediary factor-2 modified the transactivation of the mutants significantly in vitro (Ghali et al. 2003, Umar et al. 2005). In this study, the effect of cofactors was not investigated, but cofactors of AR and WT1 should be considered for future studies of AR transactivation by WT1. Furthermore, the most physiologic in vitro cell system to investigate the effects of transcription factors on AR expression in urogenital development would be 
a human embryonic mesenchymal cell line from the urogenital tract as WT1 and the AR were found to be colocalized in this cell type around the UGS. But, to date, such a cell line is not available.

Also notable is the expression of WT1 in the Müllerian duct epithelium and mesenchymal cells of the mesonephros. WT1 and AMH were found to be coexpressed in Sertoli cells and WT1 was shown to activate AMH in synergy with SF-1 (Nachtigal et al. 1998). The expression of WT1 in the Müllerian duct indicates that WT1 also might have a direct impact on Müllerian duct regression. Interestingly, the AMH receptor was not found to be expressed in the epithelium of the Müllerian duct, but only in the surrounding interstitium and it was demonstrated that paracrine factors are involved in apoptosis of the Müllerian ducts (Roberts et al. 1999, Teixeira et al. 2001). Since WT1 is known to play a role in apoptosis, it can be suggested that it might be implicated in the cellular crosstalk of Müllerian duct regression (Menke et al. 1998). Unfortunately, data on development of Müllerian structures in patients with WT1 mutations are too scarce to address this hypothesis (Auber et al. 2003).

So far, HOXA13 (Homeobox A13) is the only described early developmental gene, in which mutations result in hypospadias with impaired embryonic AR expression. HOXA13 mutations were described to cause hand-foot-genital syndrome with hypospadias in humans (Mortlock \& Innis 1997, Goodman et al. 2000). Interestingly, in the Hoxa-13 mutant mouse model, AR expression in the mesenchyme proximal and lateral to the hypospadic region was decreased (Morgan et al. 2003). These data gave evidence that the AR might also be influenced by other early developmental genes playing a role in genital organogenesis.

Our data of WT1 and AR coexpression in the mesenchyme surrounding the UGS and in the gubernaculum testis suggested that a WT1 and AR interaction could be involved in the complex process of closure of the proximal urethra and testicular descent in males through influencing mesenchymal-epithelial interactions. The role of WT1 in this process might be by modification of AR expression, but most probably in concert with other cofactors, local growth factors, or developmental genes (e.g. the fibroblast growth factor or Gli family; Yamada et al. 2006). However, studies of AR expression in the genital tract of WT1 mutant mice would provide a physiologically more relevant answer to whether WT1 might influence the AR in vivo.

\section{Acknowledgements}

This work was supported by the European Society of Paediatric Endocrinology Research Fellowship sponsored by Novo Nordisk AIS (to B K) and the Robert Welch Foundation \#I-1090 and NIH grants \#DK03892 (to M J M). The authors declare that there is no conflict of interest that would prejudice the impartiality of this scientific work.

\section{References}

Adachi M, Takayanagi R, Tomura A, Imasaki K, Kato S, Goto K, Yanase T, Ikuyama S \& Nawata H 2000 Androgen-insensitivity syndrome as a possible coactivator disease. New England Journal of Medicine 343 856-862.

Auber F, Lortat-Jacob S, Sarnacki S, Jaubert F, Salomon R, Thibaud E, Jeanpierre C \& Nihoul-Fekete C 2003 Surgical management and genotype/phenotype correlations in WT1 gene-related diseases (Drash, Frasier syndromes). Journal of Pediatric Surgery 38 124-129 discussion 124-129.

Barbaux S, Niaudet P, Gubler MC, Grunfeld JP, Jaubert F, Kuttenn F, Fekete CN, Souleyreau-Therville N, Thibaud E, Fellous M et al. 1997 Donor splice-site mutations in WT1 are responsible for Frasier syndrome. Nature Genetics 17 467-470.

Call KM, Glaser T, Ito CY, Buckler AJ, Pelletier J, Haber DA, Rose EA, Kral A, Yeger H, Lewis WH et al. 1990 Isolation and characterization of a zinc finger polypeptide gene at the human chromosome 11 Wilms' tumor locus. Cell 60 509-520.

Deeb A, Mason C, Lee YS \& Hughes IA 2005 Correlation between genotype, phenotype and sex of rearing in 111 patients with partial androgen insensitivity syndrome. Clinical Endocrinology 63 56-62.

Gessler M, Poustka A, Cavenee W, Neve RL, Orkin SH \& Bruns GA 1990 Homozygous deletion in Wilms tumours of a zinc-finger gene identified by chromosome jumping. Nature 343 774-778.

Ghali SA, Gottlieb B, Lumbroso R, Beitel LK, Elhaji Y, Wu J, Pinsky L \& Trifiro MA 2003 The use of androgen receptor amino/carboxylterminal interaction assays to investigate androgen receptor gene mutations in subjects with varying degrees of androgen insensitivity. Journal of Clinical Endocrinology and Metabolism 88 2185-2193.

Goodman FR, Bacchelli C, Brady AF, Brueton LA, Fryns JP, Mortlock DP, Innis JW, Holmes LB, Donnenfeld AE, Feingold M et al. 2000 Novel HOXA13 mutations and the phenotypic spectrum of hand-foot-genital syndrome. American Journal of Human Genetics 67 197-202.

Hastie ND 2001 Life, sex, and WT1 isoforms - three amino acids can make all the difference. Cell 106 391-394.

Hossain A \& Saunders GF 2001 The human sex-determining gene SRY is a direct target of WT1. Journal of Biological Chemistry 276 $16817-16823$

Jeanpierre C, Beroud C, Niaudet P \& Junien C 1998 Software and database for the analysis of mutations in the human WT1 gene. Nucleic Acids Research 26 271-274.

Kim J, Prawitt D, Bardeesy N, Torban E, Vicaner C, Goodyer P, Zabel B \& Pelletier J 1999 The Wilms' tumor suppressor gene (wt1) product regulates Dax-1 gene expression during gonadal differentiation. Molecular and Cellular Biology 19 2289-2299.

Kohler B, Schumacher V, l'Allemand D, Royer-Pokora B \& Gruters A 2001 Germline Wilms tumor suppressor gene (WT1) mutation leading to isolated genital malformation without Wilms tumor or nephropathy. Journal of Pediatrics 138 421-424.

Kreidberg JA, Sariola H, Loring JM, Maeda M, Pelletier J, Housman D \& Jaenisch R 1993 WT-1 is required for early kidney development. Cell 74 679-691.

Lim HN, Hughes IA \& Hawkins JR 2001 Clinical and molecular evidence for the role of androgens and WT1 in testis descent. Molecular and Cellular Endocrinology 185 43-50.

Little M \& Wells C 1997 A clinical overview of WT1 gene mutations. Human Mutation 9 209-225. 
Little M, Holmes G, Bickmore W, van Heyningen V, Hastie N \& Wainwright B 1995 DNA binding capacity of the WT1 protein is abolished by Denys-Drash syndrome WT1 point mutations. Human Molecular Genetics 4 351-358.

Melo KF, Martin RM, Costa EM, Carvalho FM, Jorge AA, Arnhold IJ \& Mendonca BB 2002 An unusual phenotype of Frasier syndrome due to IVS9+4C $>$ T mutation in the WT1 gene: predominantly male ambiguous genitalia and absence of gonadal dysgenesis. Journal of Clinical Endocrinology and Metabolism 87 2500-2505.

Menke AL, van der Eb AJ \& Jochemsen AG 1998 The Wilms' tumor 1 gene: oncogene or tumor suppressor gene? International Review of Cytology 181 151-212.

Morgan EA, Nguyen SB, Scott V \& Stadler HS 2003 Loss of Bmp7 and Fgf8 signaling in Hoxa13-mutant mice causes hypospadia. Development 130 3095-3109.

Mortlock DP \& Innis JW 1997 Mutation of HOXA13 in hand-footgenital syndrome. Nature Genetics 15 179-180.

Nachtigal MW, Hirokawa Y, Enyeart-VanHouten DL, Flanagan JN, Hammer GD \& Ingraham HA 1998 Wilms' tumor 1 and Dax-1 modulate the orphan nuclear receptor SF-1 in sex-specific gene expression. Cell 93 445-454.

Natoli TA, McDonald A, Alberta JA, Taglienti ME, Housman DE \& Kreidberg JA 2002 A mammal-specific exon of WT1 is not required for development or fertility. Molecular and Cellular Biology 22 4433-4438.

Pelletier J, Bruening W, Kashtan CE, Mauer SM, Manivel JC, Striegel JE, Houghton DC, Junien C, Habib R \& Fouser L 1991 Germline mutations in the Wilms' tumor suppressor gene are associated with abnormal urogenital development in Denys-Drash syndrome. Cell 67 437-447.

Reddy JC, Hosono S \& Licht JD 1995 The transcriptional effect of WT1 is modulated by choice of expression vector. Journal of Biological Chemistry $27029976-29982$.
Roberts LM, Hirokawa Y, Nachtigal MW \& Ingraham HA 1999 Paracrine-mediated apoptosis in reproductive tract development. Developmental Biology 208 110-122.

Scharnhorst V, van der Eb AJ \& Jochemsen AG 2001 WT1 proteins: functions in growth and differentiation. Gene 273 141-161.

Shimamura R, Fraizer GC, Trapman J, Lau YFC \& Saunders GF 1997 The Wilms' tumor gene WT1 can regulate genes involved in sex determination and differentiation: SRY, Mullerian-inhibiting substance, and the androgen receptor. Clinical Cancer Research 3 2571-2580.

Teixeira J, Maheswaran S \& Donahoe PK 2001 Mullerian inhibiting substance: an instructive developmental hormone with diagnostic and possible therapeutic applications. Endocrine Reviews 22 657-674.

Umar A, Berrevoets CA, Van NM, van Leeuwen M, Verbiest M, Kleijer WJ, Dooijes D, Grootegoed JA, Drop SL \& Brinkmann AO 2005 Functional analysis of a novel androgen receptor mutation, Q902K, in an individual with partial androgen insensitivity. Journal of Clinical Endocrinology and Metabolism 90 507-515.

Wagner KD, Wagner N \& Schedl A 2003 The complex life of WT1. Journal of Cell Science 116 1653-1658.

Wilhelm D \& Englert C 2002 The Wilms tumor suppressor WT1 regulates early gonad development by activation of Sf1. Genes and Development 16 1839-1851.

Yamada G, Suzuki K, Haraguchi R, Miyagawa S, Satoh Y, Kamimura M, Nakagata N, Kataoka H, Kuroiwa A \& Chen Y 2006 Molecular genetic cascades for external genitalia formation: an emerging organogenesis program. Developmental Dynamics 235 1738-1752.

Received in final form 16 February 2007

Accepted 22 February 2007

Made available online as an Accepted Preprint 13 March 2007 